\title{
Response of Diaphorina citri Kuwayama (Hemiptera: Psyllidae) to Volatiles Emitted from Leaves of Two Rutaceous Plants
}

\author{
Hassan Sule \\ Department of Plant Protection, Faculty of Agriculture, Universiti Putra Malaysia \\ 43400 UPM, Serdang Selangor, Malaysia \\ Department of Crop Science, Faculty of Agriculture, Adamawa State University \\ P. M. B. 25 Mubi 6500001, Adamawa State, Nigeria \\ E-mail: hansul71@yahoo.com
}

Rita Muhamad (Corresponding author)

Department of Plant Protection, Faculty of Agriculture

Universiti Putra Malaysia, 43400 UPM, Serdang Selangor, Malaysia

E-mial: rita@agri.upm.edu.my

Dzolkhifli Omar

Department of Plant Protection, Faculty of Agriculture

Universiti Putra Malaysia, 43400 UPM, Serdang Selangor, Malaysia

E-mial: zolkifli@agri.upm.edu.my

Alvin Kah-Wei Hee.

Department of Biology, Faculty of Science

Universiti Putra Malaysia, 43400 UPM, Serdang Selangor, Malaysia

E-mial: alvinhee@putra.upm.edu.my

Received: February 21, 2012 Accepted: March 14, 2012 Online Published: April 20, 2012

doi:10.5539/jas.v4n6p152

URL: http://dx.doi.org/10.5539/jas.v4n6p152

\begin{abstract}
Diaphorina citri Kuwayama (Hemiptera: Psyllidae) is an important worldwide pest of citrus, because of its ability to vector the three phloem-restricted bacteria in the genus Candidatus Liberibacter, that cause citrus greening or huanglungbing. Studies were conducted to examine the effects of flush growth stage and volatile compounds emitted by two rutaceae plants on oviposition and feeding site selection of $D$. citri. Three methods including choice, no choice and Y tube olfactometer assays were conducted using plants with only newly expanded leaves (4-6 days old), plants with all leaves completely hardened (14-21 days old) and plants without leaves (14-21 days old). The results showed that significant number of adult $D$. citri were attracted to plants with newly expanded leaves for oviposition and feeding in both choice and no choice assay, and when the two plants were assayed together in $\mathrm{Y}$ tube, significant number of the adults select $\mathrm{Y}$ tube arm with Citrus suhuiensis leaves and similarly in choice assay more adults select $C$. suhuiensis for oviposition and feeding than Murraya paniculata. The results gave an insight into response of $D$. citri to different plant forms and volatiles emitted by the plant which is useful in monitoring and management of the pest.
\end{abstract}

Keywords: Huanglungbing, Citrus suhuiensis, Choice assay, Psyllids

\section{Introduction}

The Asian citrus psyllid D. citri is placed among the most important and destructive pest of citrus globally, because of its ability to vector the three phloem-restricted bacteria in the genus Candidatus Liberibacter, (Wenninger et al., 2008) that cause citrus greening or huanglungbing (Hall et al., 2011; Mann et al., 2010 ). 
Adults and nymphs of psyllids are phytophagous and feeding damage by D. citri can result in stunted and shriveled shoots, curled and notched leaves, defoliation, flower drop, irregular-shaped canopies and branch death (die back), especially when psyllid densities are high (Shivankar et al., 2000; Yang et al., 2006). In addition, honeydew excreted by nymphs leads to blemishing of foliage and fruit and can also reduce photosynthesis (Wang et al., 2001). Citrus tree infected with greening diseases produce bitter, inedible, and misshapen fruits and eventually die within 5-10 years of infection (Mann et al., 2010; Bove 2006; Aubert, 1990)

Volatile chemical cues play an important role in insect and plant interactions; they are generally detected at some distance from the source by sensilla on the antennae of adult insects (Visser, 1986). They can also be used at closer range in combination with contact chemical cues to determine the identity of a potential host plant (Heinz 2008). The general assumption that chemical cues are of paramount importance in host finding and acceptance by herbivorous insects, whereas non chemical plant stimuli such as forms play only a secondary role has been questioned (Degen and Stadler 1997 ). According to Harris and Rose, (1990) and Roessingh and Stadler (1990) extensive studies with phytophagous fly species have revealed the potentially strong influence of physical plant properties on the host-selection behavior. Similarly visual cues were reported to be involved in host finding behavior in other species within the Sternorrhyncha, especially in the Aphididae (Doring and Chittka 2007), also Hall et al., (2007) suggests a visual role in orientation of D. citri to host plants. Nevertheless, evidence of attraction to host plant volatiles has been shown explicitly in four species in the Psylloidea: Heteropsylla cubana, Cacopsylla bidens (Sulc), Cacopsylla melanoneura (Forster) and Cacopsylla picta (Forster) (Wenninger et al., 2008).

Despite the prior works with Psylloidea and host plant volatiles, little or none have done with D. citri in South East Asia were the pest remains a major threat to Citrus cultivation. Therefore this study was undertaken to evaluate the effects volatiles emitted by two rutaceous (Citrus suhuiensis variety limau madu and Murraya paniculata) plant on egg-laying and feeding site selection of $D$. citri.

\section{Materials and Methods}

\subsection{Source and Rearing of D. citri}

Laboratory colonies of Asian citrus psyllid D. citri were established on potted citrus plant (Orange Jasmine) with nymphs and adults collected from citrus tree in a deserted citrus orchard. These insects were transferred to Orange jasmine plants in glasshouse. Ten or more nymphs or adults of $D$. citri were placed in a screen cage measuring $70 \times 70 \times 70 \mathrm{~cm}$ containing one jasmine plant with new flush of vegetative shoots, the insects were allowed to remain on plants in the cage until when they laid eggs on the new developing shoots, thereafter, they were removed to avoid overcrowding of nymphs. The F1 adults from the cage jasmine plant were used subsequently to generate more colonies of $D$. citri and the plant were regularly pruned and fertilized to promote production of new growth that is preferred for oviposition by adult female $D$. citri, and glasshouse conditions was maintained during the culturing.

To obtain adults $D$. citri of known age to be used in the experiment, fifth-instar nymphs were collected and transferred individually to M. paniculata seedlings (2-3 leaf stage) caged in plastic containers measuring $6.7 \mathrm{~cm}$ in diameter and $10 \mathrm{~cm}$ long, and the open end covered with muslin cloth and tied firmly with rubber band.

\subsection{Response of Adult D. citri to Flush Growth Stage and Host Odor}

A Choice and no-choice experiments with five replications were conducted using 10 to $12 \mathrm{~cm}$ tall rutaceae plants (Citrus suhuiensis and M. paniculata), with only newly expanded leaves (4-6 days old), with only completely hardened leaves (14- 21 days old) and stem without leaves (14-21 days old), in a screen cage. Adult male and female $D$. citri of similar age were introduced individually into each cage, by placing glass vials containing the $D$. citri at two extreme end of the cage in no choice experiment, while in choice experiment the glass vials are placed at the centre of the cage. After 24 hours the adult psyllids were observed for feeding site selected and the number of eggs laid was counted under microscope. But in the case of choice experiment between the different leave growth stages of the two plants combined together, three pairs of adult $D$. citri were introduced.

A similar experiments (choice and no-choice) as above were conducted, but the D. citri were allowed 48 and 72 hour exposure to the plants.

The treatment combinations for the choice experiment were: 1) between the different flush growth stage and plant without leaves of the same plant species, 2) between the same leave growth stage of the two different plant species, 3) between the different leave growth stage and stem without leaves of the two different plants species combined together. 


\subsection{Y-Tube Olfactometer Test}

The $\mathrm{Y}$ tube consisted of a $14 \mathrm{~cm}$ long stem and two $10 \mathrm{~cm}$ long arms, each with $2 \mathrm{~cm}$ inner diameter. A glass plug at the base of the stem was used to introduce insects into the $\mathrm{Y}$ tube and at end of each arm was a glass tube $3.5 \mathrm{~cm}$ inner diameter and $7.5 \mathrm{~cm}$ long within which odor sources were placed. Charcoal filtered humidified air was routed by polytetrafluoroethylene tubing at $300 \mathrm{ml} / \mathrm{min}$ through opening $3 \mathrm{~cm}$ away from the junction of the $\mathrm{Y}$ tube on the stem.

Adults $D$. citri of mixed sex and age were collected from $D$. citri culture with an aspirator and brought to the laboratory where they were kept in an incubator without food source for two hours in order to enhance their responses in the olfactometer. To test for attraction of host plant odor to D. citri, C. suhuiensis and M. paniculata were tested individually against a blank control and later they were tested against each other, leaves of mixed age were collected from flushing $C$. suhuiensis and M. paniculata plant and immediately wrapped in a moist paper towel and kept in plastic bag to avoid wilting. In the laboratory 10 adults $D$. citri were used to test the olfactory response under full light. For each trial (host plant) group of 10 psyllids were tested and replicated 8 times and after each trial the odor source and the $\mathrm{Y}$ tube were replaced by new ones. The number of psyllids that responded and select each olfactometer arm were counted and recorded every 10 minutes for a total period of 30 minutes.

\subsection{Statistical Analysis}

Datasets collected on olfactory test and choice and no choice experiment were subjected to two way analysis of variance using computer software (SAS 9.0 for windows) statistical package. Treatments with significant differences were compared at $0.05 \%$ level of probability using Duncan Multiple Range Test (DMRT). The two factors for the ANOVA were exposure time and plant species or plant form.

\section{Results}

\subsection{Behavioral Response of D. citri to Different Forms of C. suhuiensis and M. paniculata}

\subsubsection{No Choice Assay}

No choice test with different leaves growth stage and plants without leaves shows a significant $(\mathrm{P}<0.0001)$ difference in $D$. citri response to the different treatment. In limau madu significantly $(\mathrm{P}<0.0001)$ high number of $D$. citri responded to plant with newly expanded leaves for feeding compared to other treatment. Also significantly high number of eggs was deposited on plant with newly expanded leaves; next to it was $C$. suhuiensis with completely hardened leaves which was not different statistically from the number of eggs deposited on $C$. suhuiensis plant with no leaves (Table 1). In M. paniculata also high number of D. citri responded to plant with newly expanded leaves, but not different statistically to number responded to plant with completely hardened leaves, while in oviposition significantly high numbers of eggs were laid on plant with newly expanded leaves.

With regard to the exposure time no significant $(\mathrm{P}=0.1281)$ difference observed in number of adult $D$. citri selecting a feeding site over the 3 exposure time in both C. suhuiensis and M. paniculata (Table 1), but significantly high number of eggs were deposited over 72 hours exposure time compared to the remaining exposure time in both C. suhuiensis and M. paniculata.

\subsubsection{Choice Assays}

Choice assay within the different flush growth stage and plant without leaves of the same plant species showed that significantly high number of adult $D$. citri select plant with newly expanded leaves compared with plant to plant with completely hardened leave and plant without leave in both C. suhuiensis and M. paniculata (Table 2). Similar result was observed in oviposition, but the number of eggs deposited on plant with completely hardened leaves was not different from one deposited on plant stem with no leaves (Table 2). On exposure time no significant $(\mathrm{P}=0.3837)$ difference was observed in number of adult $D$. citri selecting a feeding site over the 3 exposure time in both $C$. suhuiensis and M. paniculata (Table 2), but significantly high number of eggs were deposited over 72 hours exposure time compared to the remaining exposure time in both C. suhuiensis and M. paniculata.

When the same leaves growth stage and plant without leaves of the two different plant species were assayed, significantly $(\mathrm{P}<0.0001)$ high number of adult $D$. citri select $C$. suhuiensis for feeding compared to $M$. paniculata in both plants with newly expanded leave and plants with completely hardened leaves (Table 3), however in plants with no leaves there was no significant $(\mathrm{P}=0.1436)$ difference between the two plants. In term of oviposition significantly high number of eggs was deposited on C. suhuiensis with newly expanded leaves, but in plant with completely hardened leaves no egg was deposited on C. suhuiensis, and also no egg was 
deposited in both C. suhuiensis and M. paniculata plants with no leaves (Table 3). With regards to the exposure time, no difference was observed statistically in number of adults selecting a feeding site and number of eggs deposited over the 3 exposure period in the two leaves growth stage and plant without leaves, except in plants with newly expanded leaves, where significantly high number of egg were deposited over 72 hours exposure time compared to the remaining exposure period (Table 3 ).

When the different leaves growth stage and plant without leaves of the two plants combined were assayed together, significantly high number of adult $D$. citri select $C$. suhuiensis with newly expanded leaves for feeding compared to the remaining treatments (Table 4), and next to it was $M$. paniculata plant with newly expanded leaves, but the number of adult selecting $C$. suhuiensis with completely hardened leaves was not different with the one selecting $M$. paniculata with completely hardened leaves statistically. Similarly significantly higher numbers of eggs were deposited on $C$. suhuiensis with newly expanded leaves compared to the remaining treatments. On exposure time no significant $(\mathrm{P}=0.8950)$ difference was observed in number of adult $D$. citri selecting a feeding site over the 3 exposure time in both C. suhuiensis and M. paniculata (Table 4), but significantly more number of eggs were deposited over 72 hours exposure time compared to the remaining exposure time in both $C$. suhuiensis and M. paniculata.

\subsubsection{Y Tube Olfactometer Assays}

Generally adult psyllid responded to the olfactory cues in the $\mathrm{Y}$ tube olfactometer assay. In C. suhuiensis vs blank assay, significantly higher number of adult psyllid showed a preference for the treated arm of the olfactometer than the blank arm (Table 5). In term of number of psyllids selecting and arm over a period of exposure time, more psyllids selected an arm over 30 minute exposure time, but was not different statistically from the number of psyllids that selected an arm over 10 and 20 minute exposure time. Similarly, in $M$. paniculata vs blank assay, significantly $(\mathrm{P}=0.0001)$ higher number of adult psyllid responded to the treated arm compared to the blank (Table 6) and significant number of psyllid selected an arm over 30 minute exposure compare to 10 minute. When $C$. suhuiensis was tested against $M$. paniculata, significantly more number of adults' psyllid responded and select arm with $C$. suhuiensis leaves compared to the arm with M. paniculata leaves (Table 7), and in term of exposure time, more number of psyllid selected an arm over 20 minute exposure time but is not different statistically compared to 30 minute exposure time.

\section{Discussion}

The results presented here suggest that oviposition and feeding site selection of adult $D$. citri are influenced by the volatile and visual cues displayed by their host. Variable results were obtained by different authors with regards to behavior of psyllids when exposed to different hosts and host form, and the importance of cues in influencing behavior of insects is well documented in psylliodea notably on apple psyllids Cacopsylla picta and Cacopsylla melanoneura Knight (Gross and Mekonen, 2005) as well as other hemipterans such as Western tarnished plant bug Lygus hesperus (Blackmer and Canas, 2005) and glassy winged sharp shooter Homalodisca vitripennis Germar (Patt and Setamou, 2007). However, the influence of other rutaceous cues on behavior of psyllids is yet to be evaluated. Our results with respect to leaves growth stage and plant without leaves in the entire choice assays employed in this experiment indicated that adult psyllid showed evidence of attraction to plants with newly expanded leaves for feeding and oviposition than the other treatments. This was ascertain in no choice assay where all introduced adult $D$. citri were observed to be on the young flush leaves, while in the other treatment some $D$. citri were observed to be on the wall of the cage, suggesting influence of cue (volatile emitted or growth stage/colour or combination of both) on response of D. citri to it host. A similar result was reported by Ikeda and Ashihara (2008), in their study significantly high number of adult's $D$ citri were found to be aggregated on the buds than on the leaves of both C. unshiu and M. paniculata in a preference choice assay study. The attraction of adult $D$. citri to newly expanded leaves for feeding and oviposition in the present study may be attributed to the presence of $\mathrm{CO}_{2}$, ethylene and cuticle precursors (Harrewijn et al., 1994) that signify the presence of young shoot growth and likely emission of more volatile compounds by newly expanded leaves than completely hardened leaves and plant without leaves or explain by the fact that psyllid being a sucking pest need a tender tissue which may be easier to insert their stylet for feeding and anchoring their eggs. Furthermore the newly expanded leaves of both C. suhuiensis and M. paniculata are bright yellow in color which psyllids were reported to be innately attracted to (Wenninger et al., 2008).

Relative to the two plants our result shows preference of adult D. citri to C. suhuiensis compared to $M$. paniculata plant for feeding and oviposition irrespective of the leaves growth stage. This result agree with the findings of Tsai and Liu (2000) when they tested Murraya paniculata (orange jasmine), Citrus jambhiri (rough lemon), Citrus aurantium (sour orange), and Citrus $\times$ paradisi (grapefruit), they concluded that grapefruit was 
the most preferred host. Similarly in Zhejiang China, the preferred hosts are reported to be commercial citrus followed by M. paniculata and trifoliate orange, (Yang et al., 2006).

Although $D$.citri responded significantly to both $C$. suhuiensis and M. paniculata when assayed with blank in Y tube olfactometer, but the number responded to M. paniculata was higher than that of $C$. suhuiensis. On the other hand, significantly higher number of adult $D$. citri responded to $C$. suhuiensis when assayed with M. paniculata. Citrus foliar volatiles are reported to comprise primarily of common monoterpenes, sesquiterpenes and monoterpenes esters (Patt and Setamou, 2010). The apparent D. citri selection of the treated arm of the Y tube when assayed with blank, may be attributed to the presence of volatile compounds emitted and leaves color, while high response to $C$. suhuiensis when assayed with M. Paniculata may be explained by difference in quantity and type of volatiles emitted by them.

\section{Conclusion}

Based on evaluation of literatures and the results presented in the present study, response of $D$. citri to its host for feeding or oviposition is being influence by leaves growth stage and plant without leaves and volatiles compounds emitted by the host. But many question remain to be answered such as whether mature leaves and stem have some antifeedent and anti oviposition chemicals? Investigation into the chemistry of completely hardened leaves and stem without leaves of the host plants and identification of their active constituent may answer some of the question and pave a way for development of compounds that may be use in management of the pest.

\section{Acknowledgment}

The authors are thankful to Universiti Putra Malaysia for funding this study with research grant number RUGS 9199662.

\section{References}

Aubert, B. (1990). Integrated Activities for the Control of Huanglongbing Greening and its Vector Diaphorina citri Kuwayama in Asia. In Aubert B, Tontyaporn S, Buangsuwon D (eds) Proceedings of the Fourth FAO-UNDP International Asia Pacific Conference on Citrus Rehabilitation (pp 133-144), 4-10 February 1990. Chiang Mai, Thailand.

Blackmer, J. L., \& Canas, L. A. (2005). Visual Cues Enhance the Response of Lygus hesperus (Heteroptera: Miridae) to Volatiles from Host Plants. Environmental Entomology, 34, 1524-1533. http://dx.doi.org/10.1603/0046-225X-34.6.1524

Bove, J. M. (2006). Huanglongbing: A destructive, Newly Emerging, Century-old Disease of Citrus. Journal of Plant Pathology, 88, 7-37.

Degen, T., \& Stadler, E. (1997). Foliar Form, Colour and Surface Characteristics Influence Oviposition Behaviour of the Carrot Fly. Entomologia Experimentalis et Applicata, 83, 99-112. http://dx.doi.org/10.1023/A:1002995327121

Doring, T. F., \& L. Chittka. (2007). Visual Ecology of Aphids, A Critical Review on the Role of Colours in Host Finding. Arthropod-Plant Interactions, 1, 3-16. http://dx.doi.org/10.1007/s11829-006-9000-1

Gross, J., \& N. Mekonen. (2005). Plant Odours Influence the Host Finding Behaviour of Apple psyllids (Cacopsylla picta; C. melanoneura). IOBC WPRS Bulletin, 28, 351-355.

Hall, D. R., Wenninger, E. J., \& Hentz, M. G. (2011). Temperature Studies with the Asian Citrus Psyllid, Diaphorina citri: Cold hardiness and Temperature Thresholds for Oviposition. Journal of Insect Science, 11, 83. http://dx.doi.org/11.83/i1536-2442-11-83.pdf

Hall, D. G., Lapointe, S. L., \& Wenninger, E. J. (2007). Effects of a Particle Film on Biology and Behavior of Diaphorina citri (Hemiptera: Psyllidae) and its Infestations in Citrus. Journal of Economic Entomology, 100, 847-854. http://dx.doi.org/10.1603/0022-0493(2007)100[847:EOAPFO]2.0.CO;2

Harrewijn, P., Minks, A. K., \& Mollema. C. (1994). Evolution of Chemical Volatile Production in the Insect Plant Relationships. Chemoecology, 5(6), 55-73. http://dx.doi.org/10.1007/BF01259434

Harris, M. O., \& Rose, S. (1990). Chemical, color, and Tactile Cues Influencing Oviposition Behavior of the Hessian Fly (Diptera: Cecidomyiidae). Environmental Entomology, 19, 303-308.

Heinz, C. A. (2008). Host Plant Odor Extracts with Strong Effects on Oviposition Behavior in Papilio polyxenes Entomologia Experimentalis et Applicata, 128, 265-273. http://dx.doi.org/10.1111/j.1570-7458.2008.00717.x 
Ikeda, K., \& Ashihara, W. (2008). Preference of Adult Asian Citrus Psyllid, Diaphorina citri (Homoptera: Psyllidae) for Murraya paniculata and Citrus unshiu. Japanese Journal of Applied Entomology and Zoology, 52, 27-30. http://dx.doi.org/10.1303/jjaez.2008.27

Mann, R. S., Qureshi, J. A., Stansly, P. A., \& Stelinski, L. L. (2010) Behavioral Response of Tamarixia radiata (Waterston) (Hymenoptera: Eulophidae) to Volatiles Emanating from Diaphorina citri Kuwayama (Hemiptera: Psyllidae) and Citrus. Journal of Insect Behavior. 23, 447-458. http://dx.doi.org/10.1007/s10905-010-9228-6

Patt, J. M., \& Setamou, M. (2007). Olfactory and Visual Stimuli Affecting Host Plant Detection in Homalodisca coagulate (Hemiptera: Cicadellidae). Environmental Entomology, 36, 142-150. http://www.bioone.org/doi/full/10.1603/0046-225X\%282007\%2936\%5B142\%3AOAVSAH\%5D2.0.CO\%3B2

Patt, J. M., \& Setamou, M. (2010). Response of the Asian Citrus Psyllid to Volatiles Emitted by the Flushing Shoots of its Rutaceous Host Plant. Environmental Entomology, 39(2), 618-624. http://dx.doi.org/10.1603/EN09216

Roessingh, P., \& Stadler, E. (1990). Foliar Form, Colour and Surface Characteristics Influence Oviposition Behaviour in the Cabbage Root Fly Delia radicum. Entomologia Experimentalis et Applicata, 57, 93-100. http://dx.doi.org/10.1111/j.1570-7458.1990.tb01419.x

Shivankar, V. J., Rao, C. N., \& Singh, S. (2000). Studies on Citrus Psylla, Diaphorina citri Kuwayama: A Review. Agricultural Reviews. Karnal, India, 21, 199-204.

Tsai, J. H., \& Liu. Y. H. (2000). Biology of Diaphorina citri (Homoptera: Psyllidae) on Four Host Plants. Journal of Economic Entomology, 93, 1721-1725.

Wang, H., Chan, G., Lin, H., Gong, J., Liang, K., \& Li, X. (2001). Occurrence of Citrus Psylla, Diaphorina citri Kuwayama in Thaizhou, Zhejaing, and its Control. Plant Protection Technology and Extension, 21(3), 20-21.

Wenninger, E. J., Stelinski, L., \& Hall, D. G. E. (2008). Behavioral evidence for a Female-Produced Sex Attractant in Diaphorina citri. Entomologia Experimentalis et Applicata, 128, 450-459 http://dx.doi.org/10.1111/j.1570-7458.2008.00738.x

Visser, J. H. (1986). Host Odor Perception in Phytophagous Insects. Annual Review of Entomology, 31, 121-144. http://dx.doi.org/10.1146/annurev.en.31.010186.001005

Yang, Y., Huang, M., Andrew, C. B., Xia, Y., Ouyang, G., \& Xiong, J. (2006). Distribution, Biology, Ecology and Control of the Psyllid Diaphorina citri Kuwayama, a Major Pest of Citrus: A Status Report for China. International Journal of Pest Management, 52(4), 343-352. http://dx.doi.org/10.1080/09670870600872994

Table 1. Mean number of $D$.citri eggs and feeding site selection in no choice assay on different leaves growth stage and exposure time

\begin{tabular}{lcccc}
\hline \multirow{2}{*}{ Treatment } & \multicolumn{2}{c}{ C. suhuiensis } & \multicolumn{2}{c}{ M. paniculata } \\
\cline { 2 - 5 } $\begin{array}{l}\text { Newly expanded } \\
\text { leaves }\end{array}$ & $\begin{array}{c}\text { Feeding site } \\
\text { selection }\end{array}$ & Oviposition & $\begin{array}{c}\text { Feeding site } \\
\text { selection }\end{array}$ & Oviposition \\
Completely & $1.47^{\mathrm{a}}$ & $15.00^{\mathrm{a}}$ & $1.20^{\mathrm{a}}$ & $12.53^{\mathrm{a}}$ \\
hardened leaves & & & & \\
& $0.80^{\mathrm{b}}$ & $0.40^{\mathrm{b}}$ & $0.80^{\mathrm{a}}$ & $0.93^{\mathrm{b}}$ \\
Plant without leaves & & & & \\
& & & & \\
& $0.07^{\mathrm{c}}$ & $0.0^{\mathrm{b}}$ & $0.20^{\mathrm{b}}$ & \\
Exposure Time & & & & \\
24 Hours & & & $0.53^{\mathrm{a}}$ & $2.27^{\mathrm{c}}$ \\
48 Hours & $0.53^{\mathrm{a}}$ & $2.53^{\mathrm{c}}$ & $0.80^{\mathrm{a}}$ & $5.13^{\mathrm{b}}$ \\
72 Hours & $0.80^{\mathrm{a}}$ & $5.47^{\mathrm{b}}$ & $0.86^{\mathrm{a}}$ & $6.07^{\mathrm{a}}$ \\
\hline
\end{tabular}

Means followed by same superscripts within same column are not significantly different at $\mathrm{P}=0.05$ level of probability according to DMRT test 
Table 2. Mean number of $D$. citri eggs and feeding site selection in choice assay within different leaves growth stage of same plant and exposure time

\begin{tabular}{lcccc}
\hline & \multicolumn{2}{c}{ C. suhuiensis } & \multicolumn{2}{c}{ M. paniculata } \\
\cline { 2 - 5 } Treatment & Feeding site selection & Oviposition & Feeding site selection & Oviposition \\
\hline Newly expanded leaves & $1.80^{\mathrm{a}}$ & $14.40^{\mathrm{a}}$ & $1.66^{\mathrm{a}}$ & $13.20^{\mathrm{a}}$ \\
& & & & \\
Completely hardened leaves & $0.13^{\mathrm{b}}$ & $0.00^{\mathrm{b}}$ & $0.33^{\mathrm{b}}$ & $0.13^{\mathrm{b}}$ \\
& & & & $0.00^{\mathrm{c}}$ \\
Plant without leaves & $0.07^{\mathrm{c}}$ & $0.00^{\mathrm{b}}$ & & $0.00^{\mathrm{b}}$ \\
& & & & \\
Exposure Time & & & $0.67^{\mathrm{a}}$ & $2.27^{\mathrm{c}}$ \\
24 Hours & $0.60^{\mathrm{a}}$ & $2.53^{\mathrm{c}}$ & $0.67^{\mathrm{a}}$ & $4.80^{\mathrm{b}}$ \\
48 Hours & $0.73^{\mathrm{a}}$ & $4.93^{\mathrm{b}}$ & $0.67^{\mathrm{a}}$ & $6.27^{\mathrm{a}}$ \\
\hline
\end{tabular}

Means followed by same superscripts within same column are not significantly different at $\mathrm{P}=0.05$ level of probability according to DMRT test

Table 3. Mean number of $D$. citri eggs and feeding site selection in choice assay between same leaves growth stage of different plants and exposure time

\begin{tabular}{lcccccc}
\hline & \multicolumn{2}{c}{$\begin{array}{c}\text { Newly expanded } \\
\text { leaves }\end{array}$} & \multicolumn{2}{c}{ Completely hardened leaves } & \multicolumn{2}{c}{$\begin{array}{c}\text { Plant without } \\
\text { leaves }\end{array}$} \\
\cline { 2 - 7 } Treatment & Feeding Site & Oviposition & Feeding Site & Oviposition & Feeding Site & Oviposition \\
\hline C. suhuiensis & $1.40^{\mathrm{a}}$ & $10.67^{\mathrm{a}}$ & $1.27^{\mathrm{a}}$ & $0.00^{\mathrm{b}}$ & $0.47^{\mathrm{a}}$ & $0.00^{\mathrm{a}}$ \\
$\begin{array}{l}\text { M. paniculata } \\
\begin{array}{l}\text { Exposure } \\
\text { Time }\end{array}\end{array}$ & $0.67^{\mathrm{b}}$ & $8.47^{\mathrm{b}}$ & $0.67^{\mathrm{b}}$ & $1.13^{\mathrm{a}}$ & $0.20^{\mathrm{a}}$ & $0.00^{\mathrm{a}}$ \\
24 Hours & $1.00^{\mathrm{a}}$ & $3.30^{\mathrm{c}}$ & $0.90^{\mathrm{a}}$ & $0.50^{\mathrm{a}}$ & $0.50^{\mathrm{a}}$ & $0.00^{\mathrm{a}}$ \\
48 Hours & $1.00^{\mathrm{a}}$ & $9.50^{\mathrm{b}}$ & $1.00^{\mathrm{a}}$ & $0.50^{\mathrm{a}}$ & $0.30^{\mathrm{a}}$ & $0.00^{\mathrm{a}}$ \\
72 Hours & $1.00^{\mathrm{a}}$ & $15.90^{\mathrm{a}}$ & $1.00^{\mathrm{a}}$ & $0.70^{\mathrm{a}}$ & $0.20^{\mathrm{a}}$ & $0.00^{\mathrm{a}}$ \\
\hline
\end{tabular}

Means followed by same superscripts within same column are not significantly different at $\mathrm{P}=0.05$ level of probability according to DMRT test

Table 4. Mean number of D.citri eggs and feeding site selection in choice assay between different leaves growth stage of Citrus suhuiensis and M. paniculata plant combine together and exposure time

\begin{tabular}{lcc}
\hline Treatment & Feeding site selection & oviposition \\
\hline C. suhuiensis newly expanded leaves & $2.80^{\mathrm{a}}$ & $14.53^{\mathrm{a}}$ \\
C. suhuiensis hardened leaves & $0.93^{\mathrm{c}}$ & $0.00^{\mathrm{c}}$ \\
C. suhuiensis with no leaves & $0.00^{\mathrm{d}}$ & $0.00^{\mathrm{c}}$ \\
M. paniculata newly expanded leaves & $1.60^{\mathrm{b}}$ & $12.13^{\mathrm{b}}$ \\
M. paniculata hardened leaves & $0.67^{\mathrm{c}}$ & $0.20^{\mathrm{c}}$ \\
M. paniculata with no leaves & $0.00^{\mathrm{d}}$ & $0.00^{\mathrm{c}}$ \\
& & \\
Exposure Time & & \\
24 Hours & $1.03^{\mathrm{a}}$ & $2.50^{\mathrm{c}}$ \\
48 Hours & $1.00^{\mathrm{a}}$ & $4.57^{\mathrm{b}}$ \\
72 Hours & $0.96^{\mathrm{a}}$ & $6.37^{\mathrm{a}}$ \\
\hline
\end{tabular}

Means followed by same superscripts within same column are not significantly different at $\mathrm{P}=0.05$ level of probability according to DMRT test 
Table 5. Results of Y tube olfactometer trials examining responses of D. citri to C. suhuiensis odor vs. blank.

\begin{tabular}{lc}
\hline Treatment & Means \\
\hline C. suhuiensis & $1.38^{\mathrm{a}}$ \\
Blank & $0.50^{\mathrm{b}}$
\end{tabular}

$\begin{array}{ll}\text { Exposure time } & \\ 10 \text { minute } & 0.81^{\mathrm{a}} \\ 20 \text { minute } & 0.94^{\mathrm{a}} \\ 30 \text { minute } & 1.06^{\mathrm{a}}\end{array}$

Means followed by same superscripts within same column are not significantly different at $\mathrm{P}=0.05$ level of probability according to DMRT test

Table 6. Results of Y tube olfactometer trials examining responses of D. citri to M. paniculata odor vs blank.

\begin{tabular}{lc}
\hline Treatment & Means \\
\hline M. paniculata & $1.46^{\mathrm{a}}$ \\
Blank & $0.29^{\mathrm{b}}$ \\
Exposure time & \\
10 minute & $0.56^{\mathrm{b}}$ \\
20 minute & $0.81^{\mathrm{ab}}$ \\
30 minute & $1.25^{\mathrm{a}}$ \\
\hline
\end{tabular}

Means followed by same superscripts within same column are not significantly different at $\mathrm{P}=0.05$ level of probability according to DMRT test

Table 7. Results of $\mathrm{Y}$ tube olfactometer trials examining responses of D. citri to C. suhuiensis odor vs . M. paniculata

\begin{tabular}{lc}
\hline Treatment & Means \\
\hline C. suhuiensis & $1.67^{\mathrm{a}}$ \\
M. paniculata & $0.50^{\mathrm{b}}$ \\
Exposure time & \\
10 minute & $0.44^{\mathrm{b}}$ \\
20 minute & $1.56^{\mathrm{a}}$ \\
30 minute & $1.25^{\mathrm{a}}$ \\
\hline
\end{tabular}

Means followed by same superscripts within same column are not significantly different at $\mathrm{P}=0.05$ level of probability according to DMRT test 